\title{
Real-Life Experience of Sorafenib Treatment for Hepatocellular Carcinoma in Korea: From GIDEON Data
}

\section{Do Young Kim, MD' \\ Hye Jin Kim, MD2 \\ Kwang-Hyub Han, MD 1 \\ Sang Young Han, $\mathrm{MD}^{3}$ \\ Jeong Heo, MD ${ }^{4}$ \\ Hyun Young Woo, $\mathrm{MD}^{4}$ \\ Soon $\mathrm{Ho}$ Um, MD \\ Yeul Hong Kim, MD \\ Young Oh Kweon, $\mathrm{MD}^{6}$ \\ Ho Yeong Lim, $\mathrm{MD}^{7}$ \\ Jung Hwan Yoon, MD \\ Wan Sik Lee, MD9 \\ Byung Seok Lee, MD ${ }^{10}$ \\ Han Chu Lee, MD ${ }^{11}$ \\ Baek-Yeol Ryoo, MD ${ }^{12}$ \\ Seung Kew Yoon, MD ${ }^{13}$}

${ }^{*}$ A list author's affiliations appears at the end of the paper.

Correspondence: Seung Kew Yoon, MD

Department of Internal Medicine,

College of Medicine,

The Catholic University of Korea,

222 Banpo-daero, Seocho-gu, Seoul 06591, Korea

Tel: 82-2-2258-7534

Fax: 82-2-536-9559

E-mail: yoonsk@catholic.ac.kr

Received July 26, 2015

Accepted February 15, 2016

Published Online February 24, 2016

\begin{abstract}
Purpose
The purpose of this study is to report real life experiences of sorafenib therapy for hepatocellular carcinoma (HCC) in Korea, using a subset of data from GIDEON (Global Investigation of Therapeutic Decisions in HCC and of Its Treatment with Sorafenib; a large, prospective, observational study).
\end{abstract}

\section{Materials and Methods}

Between January 2009 and April 2012, a total of 497 patients were enrolled from 11 sites in Korea. Of these, 482 patients were evaluable for safety analyses. Case report forms of paper or electronic version were used to record safety and efficacy data from all patients.

\section{Results}

More patients of Child-Pugh A received sorafenib for $>8$ weeks than did patients of ChildPugh B (55.5\% vs. 34.3\%). Child-Pugh score did not appear to influence the starting dose of sorafenib, and approximately $70 \%$ of patients both in Child-Pugh A and B groups received the recommended initial daily dose of $800 \mathrm{mg}$ (69.0\% and $69.5 \%$, respectively). The median overall survival (OS) and time to progression (TTP) were 8.5 months and 2.5 months. In Child-Pugh A patients, the median OS and TTP were 10.2 months and 2.5 months. The most frequent treatment-emergent drug-related adverse event was hand-foot skin reaction (31.7\%), followed by diarrhea (18.0\%). The incidence of treatment-emergent adverse events was similar in both Child-Pugh A (85.4\%) and Child-Pugh B (84.8\%) patients.

\section{Conclusion}

Sorafenib was well tolerated by Korean HCC patients in clinical settings, and the safety profile did not appear to differ by Child-Pugh status. Survival benefit in Korean patients was in line with that of a previous pivotal phase III trial (SHARP).

\section{Introduction}

Hepatocellular carcinoma (HCC) represents the fifth most common cancer worldwide and is known to cause significant public health problems, particularly in association with chronic hepatitis $\mathrm{B}(\mathrm{CHB})$ or chronic hepatitis $\mathrm{C}$ [1]. Based on available data, more than half of HCC cases and deaths are estimated to occur in North Eastern Asian areas including
Key words

Hepatocellular carcinoma, Sorafenib, Korea 
at risk through a surveillance program, a substantial proportion of patients with HCC are still diagnosed at an advanced stage of the disease when the survival rate is poor [5]. Potentially curative treatments including resection, ablation, and liver transplantation can be applied only to HCC detected at an early stage (single nodule $\leq 5 \mathrm{~cm}$ or 2-3 nodules $\leq 3 \mathrm{~cm}$ ) [6]. Transarterial chemoembolization (TACE) is regarded as standard-of-care for multinodular HCC without vascular invasion and extrahepatic metastasis [7].

Sorafenib is the first developed molecular targeted agent in HCC which blocks the Raf/MEK/ERK pathway by inhibiting Raf serine/threonine kinase and also inhibiting the upstream receptor tyrosine kinases that are important in angiogenesis, such as vascular endothelial growth factor receptor (VEGFR)-2, VEGFR-3, platelet derived growth factor receptor $\beta$ and kit [8]. In a global phase III, randomized trial of 602 patients with advanced HCC, the median overall survival (OS) was 10.7 months in the sorafenib group compared with 7.9 months in the placebo group (hazard ratio, $0.69 ; 95 \%$ confidence interval, 0.55 to $0.87 ; \mathrm{p}<0.001$ ). The survival benefit was preceded by a delay in time to progression (TTP): 5.5 months for sorafenib versus 2.8 months for control $(p<0.001)$ [9]. Another phase III trial conducted in the AsiaPacific (AP) area confirmed the survival benefit of sorafenib in unresectable HCC [10]. Based on these results, sorafenib was approved as the first systemic drug for patients with advanced HCC not amenable to resection, transplantation, or locoregional treatments $[7,8]$.

Data obtained from well-controlled clinical trials might not be translated into a real-clinical setting, particularly in HCC treatment. The efficacy and safety of sorafenib in HCC patients with liver dysfunction remain largely unknown, as only patients of Child-Pugh A were included in the trials. GIDEON (Global Investigation of Therapeutic Decisions in HCC and of Its Treatment with Sorafenib) is a prospective, non-interventional study conducted to fulfil post-approval commitments to licensing agencies [11]. GIDEON is one of the largest studies conducted in patients with unresectable HCC, and the data facilitate broad evaluation of patient subgroups. Many subanalyses were therefore planned and performed, with a focus on potentially predictive or prognostic factors, including Child-Pugh score, Barcelona Clinic Liver Cancer (BCLC) stage, and etiology.

Herein, we report on real-life experience of sorafenib therapy for HCC in Korea, using a subset of the GIDEON data.

\section{Materials and Methods}

\section{The design and objectives of GIDEON}

GIDEON recruited patients who were candidates for systemic therapy, for whom the decision to treat with sorafenib was made in real-life practice conditions including patients with Child-Pugh B liver function. The details of the study design have been previously published [12]. The primary objective of GIDEON is to evaluate the safety of sorafenib in patients with unresectable HCC in real-life. The secondary objectives are to explore drug efficacy in terms of OS, progression-free survival, TTP, response rate (RR), and disease control rate (DCR); to determine the duration of therapy according to various patient characteristics; to assess methods of patient evaluation, diagnosis, and follow-up; to assess comorbidities and their influence on treatment and outcome in real-life practice rather than a controlled clinical trial setting; and to evaluate the practice pattern of the physicians involved in the care of these patients.

\section{Patients}

Eligible patients were those diagnosed histologically or radiographically with HCC, who have a life expectancy of $>8$ weeks and in whom the decision to treat with sorafenib was made by their physician. Detailed inclusion criteria are outlined in the previously published study design report [11]. Exclusion criteria were those dictated by the manufacturer of the drug. Written informed consents were given by all patients and the study was approved by the individual institutional review board. More than 3,000 patients were recruited from 39 countries of five geographic regions between January 2009 and April 2012. A total of 497 patients were enrolled from 11 sites in Korea during the same period. Of these, 482 patients were evaluable for safety analyses after exclusion of 15 patients who did not receive at least one dose of sorafenib during the study period $(n=5)$ or did not undergo at least one assessment for follow-up after initiating study medication, regardless of previous systemic treatment $(\mathrm{n}=10)$.

\section{Data collection and analyses}

Paper or electronic case report forms were used to record data from all enrolled patients at study entry and start of sorafenib, then at intervals chosen by the prescribing physician until death, withdrawal from the study, or loss to follow-up. All adverse events (AEs) were graded according to the National Cancer Institute Common Terminology Criteria ver. 3.0 (National Cancer Institute, Bethesda, MD), and their 
likely relationship to sorafenib therapy was documented. HCC assessment was made by computed tomography or other equivalent radiographical method and was evaluated using the Response Evaluation Criteria in Solid Tumors (RECIST). All efficacy and safety data were summarized using descriptive statistics.

\section{Results}

\section{Baseline patient characteristics}

The baseline demographic and tumor characteristics of 482 patients evaluable in terms of safety analysis are shown in Table 1. Male patients predominated $(85.5 \%)$, and $76.8 \%$ of patients were under 65 years of age (median age, 55.0 years). The most common underlying etiology was hepatitis B virus (HBV) infection (81.1\%), followed by alcohol use (26.3\%). Most patients were Child-Pugh A class (56.8\%), with fewer Child-Pugh B patients (21.8\%). Eastern Cooperative Oncology Group (ECOG) performance status was $1(44.8 \%)$ and $0(33.8 \%)$ in most patients.

All BCLC stages were represented but most patients $(60.8 \%)$ were BCLC stage C, while $4.8 \%$ of patients were BCLC stage $B, 4.6 \%$ stage $\mathrm{D}$, and $0.8 \%$ stage $\mathrm{A}$. In terms of TNM staging, stage III and IV patients accounted for $25.9 \%$ and $52.5 \%$ of all patients, respectively, and only a few were TNM stage I $(0.2 \%)$ or II $(1.9 \%)$. Portal vein thrombosis was observed in $50.4 \%$ of patients and extrahepatic spread in $66.0 \%$. Prior locoregional treatment (LRT) was administered in $68.3 \%$ of all patients, with TACE being the most common. Thus, $60.6 \%$ of all patients had undergone prior TACE compared with $14.5 \%, 8.3 \%$, and $2.1 \%$ of patients treated with prior radiofrequency ablation, hepatic arterial infusional chemotherapy, or percutaneous ethanol injection, respectively.

\section{Sorafenib administration}

Data on sorafenib administration are shown in Table 2. The mean duration of treatment was 15 weeks (median, 8.7 weeks). Approximately $67 \%$ of patients received the approved initial daily dose of $800 \mathrm{mg}$, while $31.5 \%$ received a half dose $(400 \mathrm{mg})$. Only a few patients received $200 \mathrm{mg}$ or $600 \mathrm{mg}$ as an initial daily dose ( $0.6 \%$ and $0.8 \%$, respectively). Patients were most frequently treated for $4-8$ weeks $(22.0 \%)$, followed by $\leq 4$ weeks $(21.4 \%)$ and $>28$ weeks $(12.7 \%)$.

Analysis of sorafenib dosing was based on Child-Pugh class (A or B) (Table 2). The duration of sorafenib administration was generally longer in Child-Pugh $A$ than $B$ patients.
Table 1. Baseline patient characteristics

\begin{tabular}{|c|c|}
\hline Variable & No. $(\%)(\mathrm{n}=482)$ \\
\hline \multicolumn{2}{|l|}{ Age (yr) } \\
\hline Mean \pm SD & $55.9 \pm 10.5$ \\
\hline Median & 55.0 \\
\hline$<65$ & $370(76.8)$ \\
\hline 65 to $<75$ & $95(19.7)$ \\
\hline$\geq 75$ & $17(3.5)$ \\
\hline \multicolumn{2}{|l|}{ Sex } \\
\hline Male & 412 (85.5) \\
\hline Female & 70 (14.5) \\
\hline \multicolumn{2}{|l|}{ Etiology of $H_{C C}{ }^{a)}$} \\
\hline $\mathrm{HBV}$ & $391(81.1)$ \\
\hline $\mathrm{HCV}$ & $26(5.4)$ \\
\hline Alcohol & $127(26.3)$ \\
\hline Unknown & $22(4.6)$ \\
\hline \multicolumn{2}{|l|}{ Cirrhosis } \\
\hline Yes & 307 (63.7) \\
\hline No & $101(21.0)$ \\
\hline Unknown & $74(15.4)$ \\
\hline \multicolumn{2}{|l|}{ Child-Pugh class } \\
\hline A & $274(56.8)$ \\
\hline B & $105(21.8)$ \\
\hline $\mathrm{C}$ & $6(1.2)$ \\
\hline Unknown & $97(20.1)$ \\
\hline \multicolumn{2}{|l|}{ BCLC stage } \\
\hline A & $4(0.8)$ \\
\hline B & $23(4.8)$ \\
\hline $\mathrm{C}$ & $293(60.8)$ \\
\hline $\mathrm{D}$ & $22(4.6)$ \\
\hline Unknown & $140(29.0)$ \\
\hline \multicolumn{2}{|l|}{ TNM stage } \\
\hline I & $1(0.2)$ \\
\hline II & $9(1.9)$ \\
\hline IIIa & $72(14.9)$ \\
\hline $\mathrm{IIIb}$ & $19(3.9)$ \\
\hline IIIc & $34(7.1)$ \\
\hline IV & $253(52.5)$ \\
\hline Unknown & $94(19.5)$ \\
\hline Portal vein thrombosis & $243(50.4)$ \\
\hline Extrahepatic spread & $318(66.0)$ \\
\hline \multicolumn{2}{|l|}{ ECOG at start of therapy } \\
\hline 0 & $163(33.8)$ \\
\hline 1 & $216(44.8)$ \\
\hline$\geq 2$ & $36(7.5)$ \\
\hline Unknown & $37(13.9)$ \\
\hline \multicolumn{2}{|l|}{ Prior anti-cancer therapy } \\
\hline LRT & $329(68.3)$ \\
\hline TACE & $292(60.6)$ \\
\hline RFA & 70 (14.5) \\
\hline HAIC & $40(8.3)$ \\
\hline PEI & $10(2.1)$ \\
\hline
\end{tabular}

$\mathrm{SD}$, standard deviation; HCC, hepatocellular carcinoma; $\mathrm{HBV}$, hepatitis $\mathrm{B}$ virus; $\mathrm{HCV}$, hepatitis $\mathrm{C}$ virus; $\mathrm{BCLC}$, Barcelona Clinic Liver Cancer; ECOG, Eastern Cooperative Oncology Group; LRT, locoregional therapy; TACE, transarterial chemoembolization; RFA, radiofrequency ablation; HAIC, hepatic arterial infusion chemotherapy; PEI, percutaneous ethanol injection. ${ }^{\mathrm{a})}$ Multiple responses were possible for etiology of underlying disease and LRT. 
Table 2. Sorafenib administration according to Child-Pugh class

\begin{tabular}{|c|c|c|c|}
\hline Variable & Total $(n=482)$ & Child-Pugh A (n=274) & Child-Pugh B (n=105) \\
\hline \multicolumn{4}{|l|}{ Duration of treatment (wk) } \\
\hline Mean \pm SD & $14.93 \pm 17.36$ & $17.01 \pm 19.73$ & $8.55 \pm 8.66$ \\
\hline Median & 8.70 & 10.05 & 6.00 \\
\hline$\leq 4$ & $103(21.4)$ & $47(17.2)$ & $35(33.3)$ \\
\hline $4-8$ & $106(22.0)$ & $65(23.7)$ & $24(22.9)$ \\
\hline $8-12$ & $67(13.9)$ & $37(13.5)$ & $14(13.3)$ \\
\hline $12-16$ & $42(8.7)$ & $27(9.9)$ & $8(7.6)$ \\
\hline $16-20$ & $36(7.5)$ & $20(7.3)$ & $6(5.7)$ \\
\hline $20-24$ & $22(4.6)$ & $16(5.8)$ & $1(1.0)$ \\
\hline $24-28$ & $19(3.9)$ & $10(3.6)$ & $3(2.9)$ \\
\hline$>28$ & $61(12.7)$ & $42(15.3)$ & $4(3.8)$ \\
\hline Unknown & $26(5.4)$ & $10(3.6)$ & $10(9.5)$ \\
\hline \multicolumn{4}{|l|}{ Average daily dose (mg) } \\
\hline Mean \pm SD & $626.0 \pm 177.0$ & $626.8 \pm 173.0$ & $640.3 \pm 178.2$ \\
\hline Median & 669.5 & 661.5 & 715.0 \\
\hline Unknown (n) & 52 & 26 & 13 \\
\hline \multicolumn{4}{|l|}{ Initial dose (mg) } \\
\hline 200 & $3(0.6)$ & $1(0.4)$ & $1(1.0)$ \\
\hline 400 & $152(31.5)$ & $83(30.3)$ & $29(27.6)$ \\
\hline 600 & $4(0.8)$ & $1(0.4)$ & $2(1.9)$ \\
\hline 800 & $323(67.0)$ & $189(69.0)$ & $73(69.5)$ \\
\hline $\begin{array}{l}\text { Permanent discontinuation } \\
\text { of sorafenib due to } \mathrm{AE}\end{array}$ & $127(26.3)$ & 81 (29.6) & $34(32.4)$ \\
\hline
\end{tabular}

Values are presented as number (\%) unless otherwise indicated. Data for patients with not evaluable Child-Pugh status $(\mathrm{n}=97)$ and Child-Pugh $\mathrm{C}(\mathrm{n}=6)$ is not included in this table. SD, standard deviation; AE, adverse event.

More Child-Pugh A patients received sorafenib for $>8$ weeks compared with Child-Pugh B patients (55.5\% vs. 34.3\%). However, some Child-Pugh B patients were treated for longer periods, and $3.8 \%$ of Child-Pugh B patients received $>28$ weeks of sorafenib therapy. Child-Pugh score did not appear to influence the starting dose of sorafenib; approximately $70 \%$ of patients in both Child-Pugh A and B class received the recommended initial daily dose of $800 \mathrm{mg}$ (69.0\% and $69.5 \%$, respectively) and the median daily dose was slightly lower in Child-Pugh A patients than B patients (661.5 mg vs. $715.0 \mathrm{mg}$ ). The frequency of permanent discontinuation of sorafenib due to AEs was similar between ChildPugh A and B patients (29.6\% and $32.4 \%$, respectively).

\section{Response to sorafenib and treatment outcomes}

Response to sorafenib was assessed using intent-to-treat analysis (ITT) of all patients who received at least one dose of sorafenib. A total of 490 patients were valid for the ITT set. According to RECIST criteria, three patients $(0.61 \%)$ achieved complete response (CR), while partial response (PR) and stable disease (SD) were observed in $10(2.04 \%)$ and 131
(26.73\%) patients. There were $247(50.41 \%)$ patients who showed progressive disease (Table 3). The objective RR $(\mathrm{CR}+\mathrm{PR})$ was $2.65 \%$ and the DCR, defined as proportion of patients with the best response rating of documented CR, PR, or SD maintained for at least 28 days from the first demonstration of that rating, was $79(16.12 \%)$. Of 13 patients who achieved an objective response, the median time to response was 65 days and the median duration of response was 556 days. The median duration of SD was 68 days.

The median OS and TTP were 8.5 months and 2.5 months, respectively (Fig. 1). In particular, the median OS and TTP in Child-Pugh A patients was 10.2 months and 2.5 months. Of note, the OS and TTP appeared to be longer in patients whose starting dose was $800 \mathrm{mg}$ rather than $400 \mathrm{mg}$. The OS and TTP were 9.3 and 2.8 months in patients with a starting dose of $800 \mathrm{mg}$, compared to 7.8 and 2.4 months in those with $400 \mathrm{mg}$, respectively (Table 4).

\section{Safety assessments}

At least one treatment-emergent adverse event (TEAE) was reported for $82.2 \%$ of patients (Table 5), and 293 patients 
Table 3. Response to sorafenib by intent-to-treat analysis

\begin{tabular}{lccc} 
Response & No. $(\mathbf{n = 4 9 0 )}$ & Rate $(\%)$ & 90\% CI $(\%)$ \\
Complete response & 3 & 0.61 & $0.17-1.57$ \\
Partial response & 10 & 2.04 & $1.11-3.44$ \\
Stable disease $)^{\mathrm{a}}$ & 131 & 26.73 & $23.45-30.22$ \\
Progressive disease & 247 & 50.41 & $46.60-54.22$ \\
Not assessable & 99 & 20.20 & $17.26-23.42$ \\
Objective response $^{(3)}$ & 13 & 2.65 & $1.58-4.19$ \\
Disease control rate $^{\mathrm{b})}$ & 79 & 16.12 & $13.45-19.11$ \\
\hline
\end{tabular}

Tumor response was assessed by Response Evaluation Criteria in Solid Tumors (RECIST) ver. 1.0. Denominator for rates $(\%)$ and $90 \%$ confidence interval (CI) were based on patient population for analysis. ${ }^{\text {a) }}$ Stable disease: patients with best overall response of stable disease at least 6 weeks after first dose of sorafenib, bisease control rate: patients with best response rating of documented complete response, partial response, or stable disease maintained for at least 28 days from the first demonstration of that rating.

A

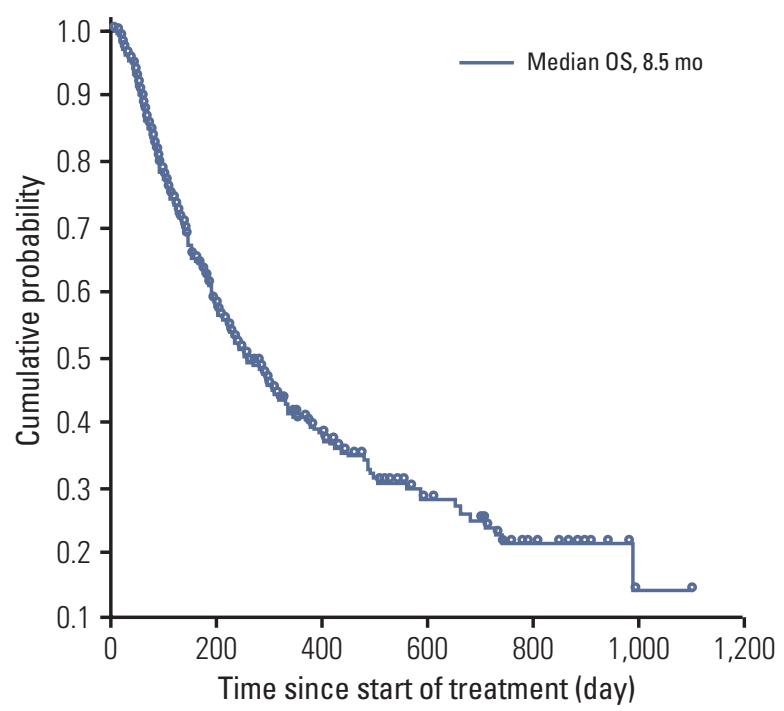

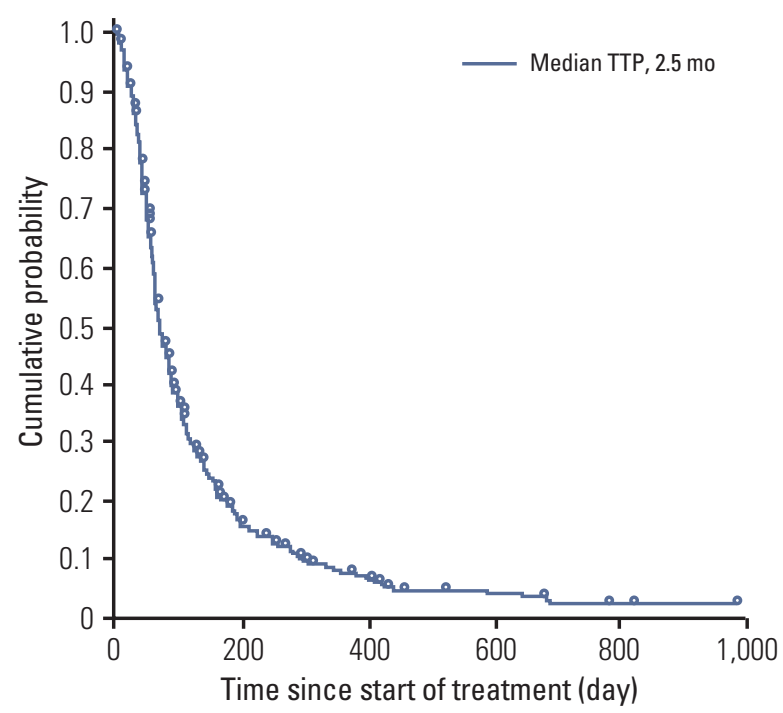

Fig. 1. The median overall survival (OS) (A) and time to progression (TTP) (B) in the entire study population was 8.5 months and 2.5 months, respectively. The response was estimated based on Response Evaluation Criteria in Solid Tumors ver. 1.0.

$(60.8 \%)$ experienced drug-related TEAEs. Of these, $16.2 \%$ patients had grade 3 events and $0.8 \%$ of patients had grade 4 events. Overall, $36.9 \%$ of patients ( $\mathrm{n}=178)$ experienced treatment-emergent serious adverse events (SAEs) and $4.4 \%$ experienced treatment-emergent drug-related SAEs. Sorafenib was permanently discontinued as a result of TEAEs in $26.3 \%$ of patients.

The incidence of TEAEs was similar between Child-Pugh A (85.4\%) and Child-Pugh B (84.8\%) patients (Table 5). However, the incidence of drug-related TEAEs and that of grade 3 TEAEs was higher in Child-Pugh A than B patients (treat- ment-emergent drug-related AEs, $66.4 \%$ vs. $56.2 \%$; grade 3 TEAEs, $28.5 \%$ vs. 18.1\%). Treatment-emergent SAEs occurred more often in Child-Pugh B than A patients (52.4\% vs. $34.3 \%$ ). Treatment-emergent drug-related SAEs occurred in $4.4 \%$ of Child-Pugh A and $7.6 \%$ of Child-Pugh B patients. The rates of sorafenib discontinuation due to AEs, regardless of any causal relationship with sorafenib, was similar in Child-Pugh A $(29.6 \%)$ and B patients $(32.4 \%)$. Treatment emergent deaths were higher in Child-Pugh B than A patients ( $28.6 \%$ vs. $10.9 \%)$.

The most commonly reported TEAEs in the overall popu- 
Table 4. Overall survival and time to progression according to the starting dose of sorafenib

\begin{tabular}{lccccc} 
Sorafenib & No. & Median OS (mo) & $95 \%$ CI (mo) & Median TTP (mo) & $95 \%$ CI (mo) \\
$400 \mathrm{mg}$ & 154 & 7.8 & $5.7-10.9$ & 2.4 & $2.0-3.0$ \\
$800 \mathrm{mg}$ & 329 & 9.3 & $7.3-12.5$ & 2.8 & $2.2-3.2$ \\
\hline
\end{tabular}

OS, overall survival; CI, confidence interval; TTP, time to progression.

Table 5. Overview of safety data by Child-Pugh score

\begin{tabular}{|c|c|c|c|c|c|}
\hline Adverse event summary & $\begin{array}{c}\text { Total } \\
(\mathrm{n}=482)\end{array}$ & $\begin{array}{l}\text { Child-Pugh A } \\
\qquad(\mathrm{n}=274)\end{array}$ & $\begin{array}{l}\text { Child-Pugh B } \\
\qquad(\mathbf{n}=\mathbf{1 0 5})\end{array}$ & $\begin{array}{l}\text { Child-Pugh C } \\
\qquad(\mathrm{n}=6)\end{array}$ & $\begin{array}{l}\text { Not evaluable } \\
\qquad(n=97)\end{array}$ \\
\hline TEAE (all grades) & $396(82.2)$ & $234(85.4)$ & $89(84.8)$ & $4(66.7)$ & $69(71.1)$ \\
\hline $\begin{array}{l}\text { Treatment-emergent } \\
\text { drug-related AE (all grades) }\end{array}$ & $293(60.8)$ & $182(66.4)$ & $59(56.2)$ & $1(16.7)$ & $51(52.6)$ \\
\hline $\begin{array}{l}\text { Treatment-emergent } \\
\text { SAE (all grades) }\end{array}$ & $178(36.9)$ & $94(34.3)$ & $55(52.4)$ & $4(66.7)$ & $25(25.8)$ \\
\hline $\begin{array}{l}\text { Treatment-emergent } \\
\text { drug-related SAE (all grades) }\end{array}$ & $21(4.4)$ & $12(4.4)$ & $8(7.6)$ & 0 & $1(1.0)$ \\
\hline $\begin{array}{l}\text { TEAE resulting in permanent } \\
\text { discontinuation of sorafenib }\end{array}$ & $127(26.3)$ & $81(29.6)$ & $34(32.4)$ & $1(16.7)$ & $11(11.3)$ \\
\hline All TEAE with CTCAE grade 3 & $120(24.9)$ & $78(28.5)$ & $19(18.1)$ & 0 & $23(23.7)$ \\
\hline $\begin{array}{l}\text { All treatment-emergent drug-related } \\
\text { AE with CTCAE grade } 3\end{array}$ & $78(16.2)$ & 49 (17.9) & $14(13.3)$ & 0 & $15(15.5)$ \\
\hline All TEAE with CTCAE grade 4 & $24(5.0)$ & $10(3.6)$ & $8(7.6)$ & 0 & $6(6.2)$ \\
\hline $\begin{array}{l}\text { All treatment-emergent drug-related } \\
\text { AE with CTCAE grade } 4\end{array}$ & $4(0.8)$ & $3(1.1)$ & 0 & 0 & $1(1.0)$ \\
\hline
\end{tabular}

Values are presented as number (\%). Adverse event (AE) was assessed by National Cancer Institute Common Toxicity Criteria (NCI CTC) ver. 3.0 and worst grade. A serious adverse event (SAE) is defined as any AE occurring at any dose that results in any of the following outcomes: death; life-threatening; hospitalization or prolongation of existing hospitalization; persistent or significant disability / incapacity; congenital anomaly / birth defect; medically important event. TEAE, treatment-emergent adverse event; CTCAE, Common Terminology Criteria for Adverse Events.

lation included hand-foot skin reaction $(32.2 \%)$, diarrhea $(22.8 \%)$, and abdominal pain (20.1\%) (Table 6). Hand-foot skin reaction $(6.0 \%)$, bilirubin elevation $(5.2 \%)$, and thrombocytopenia (4.5\%) were the most commonly reported grade 3 or 4 AEs in Korea, while the most common grade 4 AEs were liver dysfunction $(1.2 \%)$ and bilirubin elevation $(0.8 \%)$. The most frequent treatment-emergent drug-related $\mathrm{AE}$ was hand-foot skin reaction $(31.7 \%)$, followed by diarrhea $(18.0 \%)$, rash/desquamation $(9.3 \%)$, and anorexia $(8.1 \%)$. The safety profile of Child-Pugh B patients was generally consistent with the overall safety profile.

\section{Discussion}

GIDEON is the largest, prospective, non-interventional global study to investigate the treatment of patients with unresectable HCC in the real world, and reflects the current practice of participating physicians [12].

Looking at the final global data, a total of 3,371 patients were enrolled from 39 countries across five different regions and data on 3,202 patients were available for safety analysis [13]. In terms of etiology, the frequency of $\mathrm{HBV}$ infection was similar to that of hepatitis C virus infection globally (36.5\% vs. $32.9 \%$ ). Of all patients, $52 \%$ were BCLC stage C, while $20 \%$ of patients had BCLC-B. Regarding Child-Pugh class, sorafenib was prescribed in $20.8 \%$ of Child-Pugh B patients, indicating the real-life pattern of sorafenib use in treatment 
Table 6. Incidences of treatment-emergent and treatment-emergent drug-related adverse events (AE)

\begin{tabular}{|c|c|c|c|c|}
\hline \multirow{2}{*}{$\mathbf{A E}^{\mathrm{a})}$} & \multicolumn{2}{|c|}{ Treatment-emergent AEs } & \multicolumn{2}{|c|}{ Treatment-emergent drug-related AEs } \\
\hline & Total $(n=482)$ & Grade 3 or $4(n=482)$ & Total $(n=482)$ & Grade 3 or $4(n=482)$ \\
\hline Any AE & $396(82.2)$ & $144(29.9)$ & $293(60.8)$ & $82(17.0)$ \\
\hline Blood/bone marrow & $56(11.6)$ & $36(7.4)$ & $40(8.3)$ & $22(4.6)$ \\
\hline Thrombocytopenia & $34(7.1)$ & $22(4.5)$ & $27(5.6)$ & $15(3.1)$ \\
\hline Constitutional symptoms & $110(22.8)$ & $9(1.9)$ & $37(7.7)$ & $2(0.4)$ \\
\hline Fatigue & $50(10.4)$ & $4(0.8)$ & $28(5.8)$ & $2(0.4)$ \\
\hline Fever & $41(8.5)$ & $1(0.2)$ & $7(1.5)$ & - \\
\hline Dermatology/Skin & $202(41.9)$ & $36(7.5)$ & $190(39.4)$ & $34(7.1)$ \\
\hline Alopecia & $32(6.6)$ & - & $31(6.4)$ & - \\
\hline Hand-foot skin reaction & $155(32.2)$ & $29(6.0)$ & $153(31.7)$ & $29(6.0)$ \\
\hline Rash/Desquamation & $53(11.0)$ & $5(1.0)$ & $45(9.3)$ & $5(1.0)$ \\
\hline Gastrointestinal & $236(49.0)$ & $46(9.5)$ & $153(31.7)$ & $16(3.3)$ \\
\hline Anorexia & $69(14.3)$ & $8(1.7)$ & $39(8.1)$ & $3(0.6)$ \\
\hline Ascites & $40(8.3)$ & $18(3.7)$ & - & - \\
\hline Constipation & $24(5.0)$ & - & $6(1.2)$ & - \\
\hline Diarrhea & $110(22.8)$ & $10(2.1)$ & $87(18.0)$ & $9(1.9)$ \\
\hline Distension & $25(5.2)$ & $3(0.6)$ & $1(0.2)$ & - \\
\hline Heartburn & $29(6.0)$ & - & $15(3.1)$ & - \\
\hline Mucositis in oral cavity & $25(5.2)$ & $1(0.2)$ & $19(3.9)$ & $1(0.2)$ \\
\hline Nausea & $56(11.6)$ & $2(0.4)$ & $30(6.2)$ & $1(0.2)$ \\
\hline Vomiting & $29(6.0)$ & $1(0.2)$ & $15(3.1)$ & $1(0.2)$ \\
\hline Hemorrhage/Bleeding & $63(13.1)$ & $21(4.3)$ & $19(3.9)$ & $2(0.4)$ \\
\hline Hepatobiliary/Pancreas & $53(11.0)$ & $16(3.4)$ & $4(0.8)$ & $2(0.4)$ \\
\hline Liver dysfunction & $40(8.3)$ & $9(1.8)$ & $4(0.8)$ & $2(0.4)$ \\
\hline Infection & $32(6.6)$ & $11(2.3)$ & $3(0.6)$ & $1(0.2)$ \\
\hline Lymphatics (edema) & $26(5.4)$ & $1(0.2)$ & $2(0.4)$ & - \\
\hline Metabolic/Laboratory & $68(14.1)$ & $49(10.2)$ & $10(2.1)$ & $7(1.4)$ \\
\hline Bilirubin elevation & $36(7.5)$ & $25(5.2)$ & $2(0.4)$ & $2(0.4)$ \\
\hline Neurology & $60(12.4)$ & $18(3.7)$ & $14(2.9)$ & $1(0.2)$ \\
\hline Encephalopathy & $26(5.4)$ & $13(2.7)$ & $3(0.6)$ & $1(0.2)$ \\
\hline Pain & $161(33.4)$ & $31(6.4)$ & - & $37(7.7)$ \\
\hline Abdominal pain & $97(20.1)$ & $18(3.7)$ & - & $17(3.5)$ \\
\hline Pulmonary/Upper respiratory & $80(16.6)$ & $9(1.9)$ & - & $12(2.5)$ \\
\hline Cough & $26(5.4)$ & - & - & - \\
\hline Dyspnea & $31(6.4)$ & $8(1.7)$ & - & $1(0.2)$ \\
\hline
\end{tabular}

Values are presented as number (\%). a)Assessed by National Cancer Institute Common Terminology Criteria for Adverse Events (NCI CTCAE) ver. 3.0.

of HCC. One-third of all patients had portal vein thrombosis. The proportion of patients having undergone previous LRT was $57.5 \%$. In Korean data (total, 482 patients), the most common cause of HCC was HBV infection (81.1\%). The frequency of advanced stage (BCLC-C) (60.8\%) tended to be higher than the global figure, but the proportion of patients with decreased liver function (Child-Pugh B) (21.8\%) was similar to the global proportion, although unknown was $20.1 \%$. Portal vein thrombosis was more common in Korea $(50.4 \%)$, and more patients had been previously treated with locoregional therapy $(68.3 \%)$, and $66 \%$ of patients had extrahepatic spread.

Overall, Korean patients treated with sorafenib had more advanced diseases and more unfavorable prognosis than patients from other countries.

The drug safety profile was consistent with both those of previously published phase III trials and the final GIDEON data (Table 5) $[9,10,13]$; the most common drug-related AEs were hand foot skin reaction $(31.7 \%)$ and diarrhea $(18 \%)$. Collectively, the incidence of AEs including SAEs and treat- 
Table 7. Survival benefit of sorafenib in studies

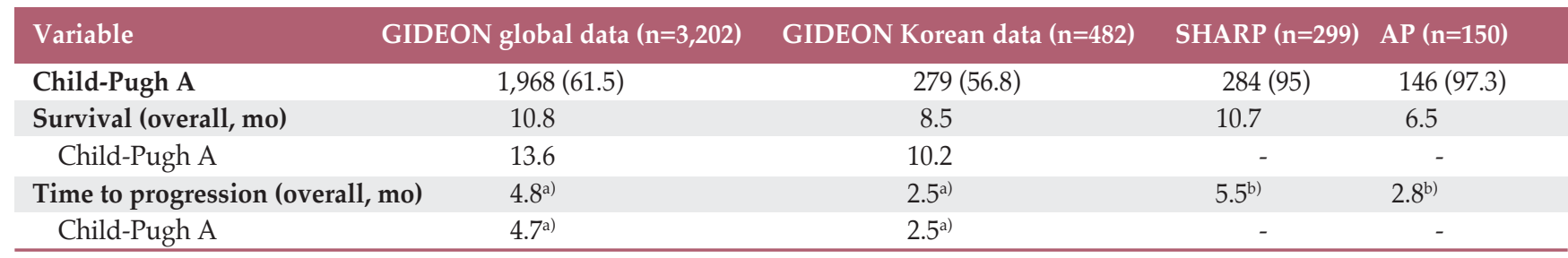

Values are presented as number (\%). GIDEON, Global Investigation of Therapeutic Decisions in hepatocellular carcinoma

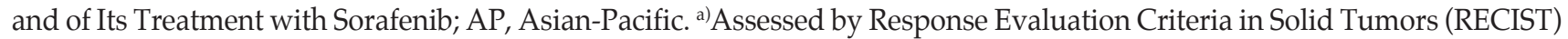

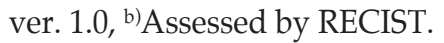

ment-emergent AEs was similar in Child-Pugh A and B patients, and in particular, Child-Pugh B did not appear to increase drug-related AEs or the rate of permanent sorafenib discontinuation, compared to Child-Pugh A (Table 4). A possible explanation for this is the consistent pharmacokinetics (PK) of sorafenib in Child-Pugh A and B patients. The PK data indicate that the maximal concentration and the geometric means of area under curve at steady state were not significantly different between Child-Pugh A and B patients. This characteristic of PK might make Child-Pugh score less influential on the safety of sorafenib treatment [14].

Although a non-interventional study cannot thoroughly evaluate drug efficacy, and data interpretation must be done with caution, we sought to determine the efficacy of sorafenib in Korean HCC patients in a real life practice setting. The median OS was 8.5 months, and thus seems superior to that observed in the AP phase III study, even though more BCLC-B patients were included in GIDEON ( $11.2 \%$ vs. $4.7 \%)$ [10]. However, we also have to consider that the majority of patients in the AP study were of Child-Pugh A. If only ChildPugh A patients are considered, the median OS is 13.6 and 10.2 months in global and Korean data, respectively, and these are superior to the AP study and seem comparable even to SHARP (10.7 months). In addition, the median TTP was 2.5 months in Korean patients with Child-Pugh A, also comparable to that of the AP trial (Table 7). Consequently, our result has confirmed the benefit of sorafenib in Korean patients with HCC, showing longer OS compared to the AP sorafenib study. Another finding from this study was the comparison of efficacy between different starting dose of sorafenib (reduced vs. full). Due to various reasons including concern of $\mathrm{AE}$ and old patient's age, starting dose of sorafenib is occasionally reduced to half $(400 \mathrm{mg}$ ) or to threefourths (600 mg). Despite several selection biases regarding comparison of efficacy between different starting doses and no analytical statistics were performed, OS in patients who received $800 \mathrm{mg}$ appeared to be longer (median survival, 9.3 months) than that of patients on $400 \mathrm{mg}$ (7.8 months). Such a result is in agreement with that from the global GIDEON trial [15]. However, further studies are necessary to clarify whether a full dose of sorafenib can result in longer survival or better baseline patient characteristics, leading physicians to start and maintain full dose of sorafenib.

Overall, the survival benefit in the Korean GIDEON study was less than that observed globally (median OS, 10.8 months globally vs. 8.5 months in Korea), probably because Korean patients presented with more advanced disease represented by high frequency of BCLC-C, Child-Pugh B, and involvement of portal vein as well as predominant etiology of CHB.

Several international guidelines suggest the use of sorafenib in treatment of Child-Pugh B patients with advanced HCC, although most enrolled patients in randomized trials were Child-Pugh A; such patients have no other treatment option because of poor liver function $[8,16]$. Sorafenib has been used in treatment of Child-Pugh B patients in Korea, and was prescribed for $21.8 \%$ of all patients. The initial dose and average daily dose in ChildPugh B patients were similar to those administered to ChildPugh A patients, and the extent of permanent treatment discontinuation triggered by development of AEs was similar in both groups. Although treatment duration tended to be shorter in Child-Pugh B patients, the most common reason for treatment discontinuation except disease progression was patient's own decision including financial reason. AE was the second most common reason; however, the incidence is not different between Child-Pugh A and B. In addition, neither the safety profile nor the incidence of AEs differed between Child-Pugh A and B patients. Accordingly, Child-Pugh score did not influence sorafenib dosing strategy and we found no evidence that AEs associated with sorafenib were more prevalent in patients with decreased liver function. Nevertheless, more prospective evidence is needed in terms of effectiveness and safety of sorafenib treatment in advanced HCC with Child-Pugh B. The interpretation of finding that the safety profile of sorafenib by the 
starting dose (800 mg vs. $400 \mathrm{mg}$ ) was not significantly different between the two groups in our study also requires caution because baseline patients' characteristics might not be similar (data not shown).

The GIDEON study is an observational study and this result is limited in data analysis due to several reasons including no control arm, selection bias, and limited data input from investigators. In particular, the economic issue of sorafenib due to non-reimbursement may affect the results regarding the cause of its discontinuation, but also the duration of therapy within this study. However, a non-interventional study can provide an opportunity to observe real clinical practice enabling the assessment of a wider patient population and this result also clearly showed the treatment pattern as well as the safety and efficacy of sorafenib in Korean HCC patients.

\section{Conclusion}

In conclusion, our study subanalyzed the Korean data from the GIDEON study and is the first, largest and prospective report on real clinical practice of sorafenib for HCC treatment in Korea. The overall results were in agreement with final data of the GIDEON study. Sorafenib was well tolerated by Korean HCC patients in real-life settings, and the drug safety profile did not appear to vary by Child-Pugh status, which also did not appear to influence the approach to sorafenib dosing, although the treatment duration was shorter in Child-Pugh B than A patients. The survival benefit of sorafenib in Korean HCC patients seems less than global data as Korean patients were in more advanced diseases. Nevertheless, the observed efficacy of sorafenib in Korean
HCC patients was consistent with that observed in earlier randomized trials (SHARP or AP) despite inclusion of more patients with Child-Pugh B.

\section{Conflicts of Interest}

The GIDEON study is funded by Bayer HealthCare Pharmaceuticals and Onyx Pharmaceuticals.

\section{Author Details}

${ }^{1}$ Department of Internal Medicine, Yonsei University College of Medicine, Seoul, ${ }^{2}$ Medical Affairs, Bayer Healthcare Pharmaceuticals, Seoul, ${ }^{3}$ Department of Internal Medicine, Donga University College of Medicine, Busan, ${ }^{4}$ Department of Internal Medicine, Pusan National University School of Medicine, Busan, ${ }^{5}$ Department of Internal Medicine, Korea University College of Medicine, Seoul, ${ }^{6}$ Department of Internal Medicine, Kyungpook National University College of Medicine, Daegu, 'Department of Medicine, Sungkyunkwan University School of Medicine, Seoul, ${ }^{8}$ Department of Internal Medicine, Seoul National University College of Medicine, Seoul, ${ }^{9}$ Department of Internal Medicine, Chonnam National University College of Medicine, Gwangju, ${ }^{10}$ Department of Internal Medicine, Chungnam National University School of Medicine, Daejeon, Departments of ${ }^{11}$ Gastroenterology and ${ }^{12}$ Oncology, University of Ulsan College of Medicine, Seoul, ${ }^{13}$ Department of Internal Medicine, College of Medicine, The Catholic University of Korea, Seoul, Korea

\section{References}

1. Kim DY, Han KH. Epidemiology and surveillance of hepatocellular carcinoma. Liver Cancer. 2012;1:2-14.

2. Ferlay J, Shin HR, Bray F, Forman D, Mathers C, Parkin DM. Estimates of worldwide burden of cancer in 2008: GLOBOCAN 2008. Int J Cancer. 2010;127:2893-917.

3. Bolondi L, Burroughs A, Dufour JF, Galle PR, Mazzaferro V, Piscaglia F, et al. Heterogeneity of patients with intermediate (BCLC B) hepatocellular carcinoma: proposal for a subclassification to facilitate treatment decisions. Semin Liver Dis. 2012;32:348-59.

4. Jeng KS, Chang CF, Jeng WJ, Sheen IS, Jeng CJ. Heterogeneity of hepatocellular carcinoma contributes to cancer progression.
Crit Rev Oncol Hematol. 2015;94:337-47.

5. Han KH, Kim DY, Park JY, Ahn SH, Kim J, Kim SU, et al. Survival of hepatocellular carcinoma patients may be impro-ved in surveillance interval not more than 6 months compared with more than 6 months: a 15-year prospective study. J Clin Gastroenterol. 2013;47:538-44.

6. Santi V, Buccione D, Di Micoli A, Fatti G, Frigerio M, Farinati $\mathrm{F}$, et al. The changing scenario of hepatocellular carcinoma over the last two decades in Italy. J Hepatol. 2012;56:397-405.

7. European Association For The Study Of The Liver; European Organisation For Research And Treatment Of Cancer. EASLEORTC clinical practice guidelines: management of hepato- 
cellular carcinoma. J Hepatol. 2012;56:908-43.

8. National Comprehensive Cancer Network. NCCN Clinical Practice Guidelines in Oncology: hepatobiliary cancers (version 2.2013) [Internet]. Fort Washington, PA: National Comprehensive Cancer Network; 2012 [cited 2014 Jun 1]. Available from: http://www.nccn.org/professionals/physician_gls/pdf/ hepatobiliary.pdf.

9. Llovet JM, Ricci S, Mazzaferro V, Hilgard P, Gane E, Blanc JF, et al. Sorafenib in advanced hepatocellular carcinoma. N Engl J Med. 2008;359:378-90.

10. Cheng AL, Kang YK, Chen Z, Tsao CJ, Qin S, Kim JS, et al. Efficacy and safety of sorafenib in patients in the Asia-Pacific region with advanced hepatocellular carcinoma: a phase III randomised, double-blind, placebo-controlled trial. Lancet Oncol. 2009;10:25-34.

11. Lencioni R, Kudo M, Ye SL, Bronowicki JP, Chen XP, Dagher $\mathrm{L}$, et al. GIDEON (Global Investigation of therapeutic DEcisions in hepatocellular carcinoma and Of its treatment with sorafeNib): second interim analysis. Int J Clin Pract. 2014; 68:609-17.

12. Lencioni R, Marrero J, Venook A, Ye SL, Kudo M. Design and rationale for the non-interventional Global Investigation of
Therapeutic DEcisions in Hepatocellular Carcinoma and Of its Treatment with Sorafenib (GIDEON) study. Int J Clin Pract. 2010;64:1034-41.

13. Marrero JA, Lencioni R, Ye SL, Kudo M, Bronowicki JP, Chen $\mathrm{XP}$, et al. Final analysis of GIDEON (global investigation of therapeutic decisions in hepatocellular carcinoma [HCC] and of its treatment with sorafenib [Sor]) in > 3000 Sor-treated patients (pts): clinical findings in pts with liver dysfunction. J Clin Oncol. 2013;31:Abstr 4126.

14. Abou-Alfa GK, Schwartz L, Ricci S, Amadori D, Santoro A, Figer A, et al. Phase II study of sorafenib in patients with advanced hepatocellular carcinoma. J Clin Oncol. 2006;24: 4293-300

15. Marrero JA, Venook A, Kudo M, Ye SL, Nakajima K, Cihon F, et al. Second interim analysis of GIDEON (global investigation of therapeutic decisions in unresectable carcinoma [uHCC] and of its treatment with sorafenib): subgroup analysis by initial sorafenib (Sor) dose. Hepatology. 2011;54:1389A.

16. Bruix J, Sherman M; American Association for the Study of Liver Diseases. Management of hepatocellular carcinoma: an update. Hepatology. 2011;53:1020-2. 